\title{
An improved automated method for the measurement of thermal thresholds. 1. normal subjects
}

\author{
GORAN A JAMAL, STIG HANSEN, ANDREW I WEIR, JOHN P BALLANTYNE
}

From the Glasgow University Department of Neurology, Institute of Neurological Sciences, Southern General Hospital, and West of Scotland Health Boards, Department of Clinical Physics and Bio-Engineering, Glasgow, Scotland, UK

SUMMARY Clinical tests of thermal sensation are poorly quantified and not strictly modality specific. Previous automated thermal testing systems have had limited usefulness with high intraand inter-individual variability. This paper describes an automated thermal system (Glasgow system) which is an extensive modification of previous techniques to answer these criticisms. It comprises a microprocessor-driven Peltier element and utilises the forced choice method of psychophysical analysis to determine the thresholds to thermal stimulation. In a control group of 106 healthy subjects the mean heat threshold for the wrist was found to be $0.23^{\circ} \mathrm{C}\left(\mathrm{SD}=0.06^{\circ} \mathrm{C}\right)$ and the mean cold threshold $0.15^{\circ} \mathrm{C}\left(\mathrm{SD}=0.05^{\circ} \mathrm{C}\right)$. Repeated determinations showed a maximum of $5 \%$ intra-individual variation in comparison to previously reported values of up to $150 \%$.

Clinical disorders of sensation are common in neurological practice and are assessed routinely at the bedside clinical examination. However, lack of sensitivity and quantitation limits the usefulness of these techniques. Early modifications of the clinical techniques of measurement of thermal sensation were inaccurate and insufficiently reproducible. ${ }^{2}$ Kenshalo introduced a thermo-electric method employing the Peltier principle, ${ }^{34}$ where the direction of current flowing in a metal thermode caused either heating or cooling. The amount of current passed gave an accurate measure of the amplitude of the stimulus. In addition, the skin temperature beneath the stimulator could be maintained at a constant predetermined value $\pm 0 \cdot 2^{\circ} \mathrm{C}$. The technique was the first to apply the stimulus without tactile cues, countering the objection that tactile stimulation of slowly adapting mechanoreceptors could be the basis for appreciation of a cold stimulus. ${ }^{5}$ Later modifications included continuous water circulation

Address for reprint requests: Dr Goran A Jamal, Department of Neurology, Institute of Neurological Sciences, Southern General Hospital, Glasgow G51 4TF, Scotland, UK.

Received 15 June 1984 and in revised form 22 August 1984. Accepted 23 August 1984 through the element to maintain background ski temperature, allowing the heat pumping capacity $\overrightarrow{0}$ the thermode to be reserved exclusively for the test or studies. $^{6}$

Simple measurements of thresholds were superseded by the "Marstock method" where the temperature interval between the perceptual thresholds for warm and cold stimuli was defined as the most sensitive index of neural abnormality..$^{7-9}$ In this interval, the "warm-cold difference limen", no thermal sensation is appreciated. These short-term studies were repeated over periods of minutes but longer term studies repeated over days showed an unsatisfactory intra-individual variation of up to $150 \%$ between estimations. ${ }^{10}$ This variability was attributed to central processing mechanisms although variation due to patient bias and reaction time had not been excluded.

The most recent studies have used automated control systems to operate the Peltier element and the "forced-choice" method of psychophysical $\frac{D}{2}$ analysis to exclude patient bias. ${ }^{112}$ However, no reports of intraindividual variation were included. ${ }^{12}$ N

This study was designed to modify the current techniques to improve sensitivity and reduce intra- $N$ individual variability to allow meaningful longitudi- $\omega$ nal studies of disorders of sensation. 


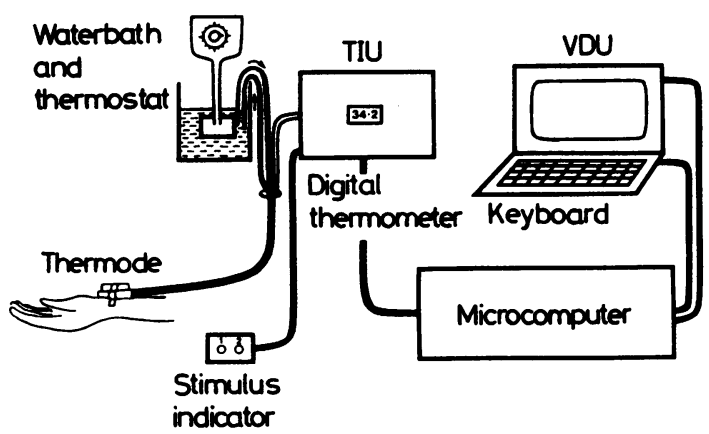

Fig 1 The Glasgow Automated Thermal System. TIU = Thermode Interface Unit; VDU = Visual Display Unit.

\section{Design}

The Glasgow thermal system is made up of the following components: a thermode, a thermode interface unit (TIU) with a digital thermometer; a stimulus indicator, a microcomputer assembly, a waterbath with a thermostat, a visual display unit (VDU) with keyboard for communication with the computer (see simplified diagram, fig 1).

The stimulating thermode, with a surface area of 12.5 $\mathrm{cm}^{2}$, is constructed from arrays of semiconducting thermo-electric elements operating by the Peltier principle. An aluminium block is mounted on the top of the thermode and is continuously perfused with circulating water at a constant temperature $\left(34.0 \pm 0.1^{\circ} \mathrm{C}\right)$ from the waterbath. The thermode surface, in contact with the skin, is heated or cooled according to the direction of the current. A thermocouple, bonded to the centre of the thermode, measures the temperature of the skin in contact with the thermode continuously. This is displayed by the digital thermometer on the TIU. The TIU contains a thermocouple amplifier with analogue to digital converter and a digital to analogue converter. The former measures and displays the skin temperature while the latter provides input to a power amplifier which drives the thermode.

The thermal stimulus output from the thermode is determined by three terms in the heat flow equation (1) The pumped Peltier heat [proportional to the current input (I)]. (2) The joule heat generated by the flow of the current through the thermode (proportional to $I^{2}$ ). (3) The heat leak back due to the difference in temperature between the junctions.

In order to maintain a specified constant power output level, it is necessary to calculate the thermode current continuously from the heat flow equation. This task is performed by the microcomputer once every $100 \mathrm{~ms}$. During the sampling interval the current is constant (equal to zero if no stimulus is applied). At the end of this interval the error in the power output, due to change in temperature difference between junctions, is less than $1 \%$. The duration of the stimulus is in multiples of the sampling intervals. A stimulus always starts and ends at the computer sampling times. The stimulus is graded by altering its duration while the power and thus the rate of change of temperature, is constant (see below).
The stimulus indicator is a small box with two light emitting diodes numbered 1 and 2 (fig 1). It is handed to the subject to watch during testing. In the testing procedure, each light is illuminated in sequence to indicate two separate time periods. During one of the periods there is a null stimulus while during the other a real stimulus is presented to the subject. The order of stimulus application is assigned randomly by the computer and is unknown to both the subject and the operator (it may be made known to the operator if desired). At the end of the trial, the subject must choose the period during which he felt the stimulus (that is forced-choice method ${ }^{13}$ ). The answer is entered into the computer which then scores a success (S) or a failure (F). This triggers the computer to give the next stimulus which is of the same, longer or shorter duration according to the up-and-down transform rule (UDTR)..$^{1214}$ The UDTR is modified in our technique so that initially, the stimulus duration, starting at 6 seconds, is reduced in steps of 1 second for each $S$ until the first $F$ which changes the direction upwards. It is after this first change in direction that the standard UDTR begins and the steps of change in stimulus duration are then of $100 \mathrm{~ms}$. For the standard UDTR, programming is such that F, SF or SSFF causes a $100 \mathrm{~ms}$ change to a higher value while SSS or SSFS causes a $100 \mathrm{~ms}$ change to a lower value. After six changes in direction (excluding the first one following the initial large steps) the threshold is calculated as the mean of the points of change in direction. The threshold value is given as the change from the basic skin temperature and

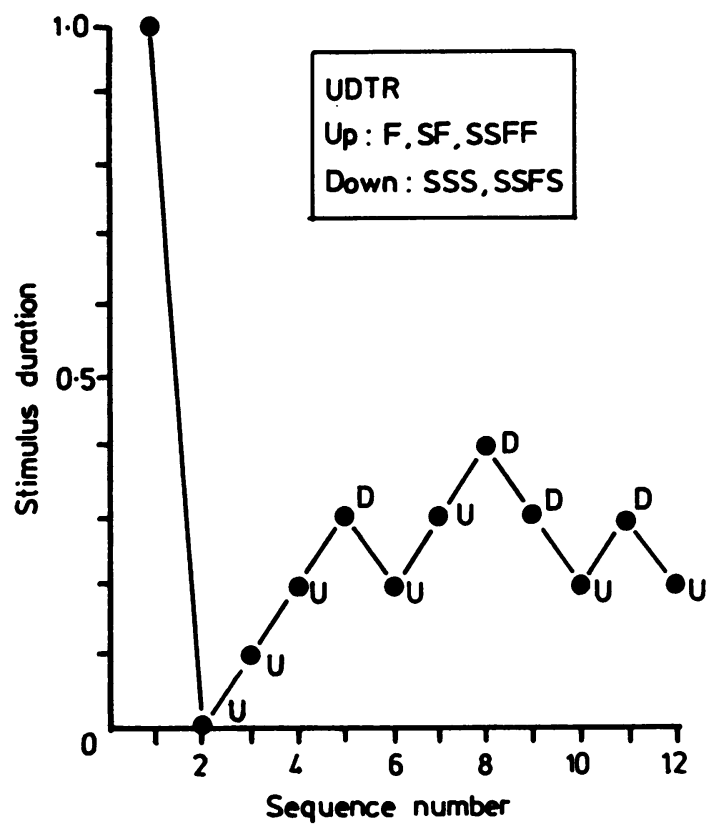

Fig 2 The graphical representation of stimulus duration (in seconds) and sequences used in the determination of each thermal threshold. UDTR $=U p$-and-Down

Transform Rule, $F=$ failure, $S=$ success. 
displayed on the VDU. Figure 2 shows a typical series of trials. The avarage number of trials needed to determine one threshold for one site was 15 (that is lasting about nine minutes). The UDTR could be started from one to nine seconds stimulus duration. In all of the normal subjects the test was started from one second stimulus duration. These modifications have two important advantages. First they allow a fast approach to the threshold level and reduce the test time considerably and secondly, they provide up to 90 levels of stimulus duration. This makes the technique very precise in determining the threshold value. In another automated method using UDTR re 21 levels of stimulus intensity are available, ma, normal people fall outside the available range. ${ }^{1112}$ The microcomputer system not only controls the thermode current but also runs the forced-choice trials and the modified UDTR.

There are certain critical aspects of the apparatus design that require further descriptions. These are as follows:

1 Thermode size. The Peltier based thermode stimulating area of $12.5 \mathrm{~cm}^{2}(25 \mathrm{~mm} \times 50 \mathrm{~mm})$ was selected as the most suitable for the skin sites examined. The variability of thermal thresholds increases with small sized probes $^{\text {is }}$ and complete contact with the skin is difficult with larger probes.

2 Thermode application. The thermode pressure on underlying skin was standardised at all sites in all subjects by adding a fixed weight to the thermode. The total mass of the thermode and the additional weight was $350 \mathrm{~g}$. The alteration of the cutaneous circulation caused by the application of the thermode was thought to be negligible (fig 1).

3 Initial skin temperature. The initial skin temperature under the probe was always kept between $34-35^{\circ} \mathrm{C}$. In a few cases this was only achieved by changing the temperature of the circulating water. This is important as variation in the initial skin temperature causes variability in the thermal thresholds. ${ }^{1517}$ At this chosen range $\left(34-35^{\circ} \mathrm{C}\right)$ the influence on thermal thresholds is minimal and complete and quick adaptation to temperature sensation occurs. ${ }^{1617}$

4 Rate of change of temperature. The rate of change of temperature was kept constant throughout in all the sites and all the subjects. Thermal thresholds, the peak discharge frequency and the cumulative number of impulses in warm nerve fibre units from human skin vary considerably with variations of rate of temperature change..$^{171016-24}$ The effect of this rate change is variable in different people.' The variation in thermal thresholds and impulse discharge frequency are at their lowest between $0 \cdot 5-1 \cdot 5^{\circ} \mathrm{C} / \mathrm{s}$ and greatest at rates below $0 \cdot 1^{\circ} \mathrm{C} / \mathrm{s} .^{12125} \mathrm{~A}$ rate of change of $1^{\circ} \mathrm{C} / \mathrm{s}$ which is the middle of the preferred range, was selected as most suitable for human skin areas ${ }^{7}$ and could be maintained fairly constant over a wide range of skin temperatures with the thermode used.

The selected rate approaches conditions of daily experience with thermal sensation. ${ }^{22}$ With a rate of $1{ }^{\circ} \mathrm{C} / \mathrm{s}$, the numerical value of change of skin temperature in ${ }^{\circ} \mathrm{C}$ is equal to the duration of stimulus application in seconds.

5 Calibration of the thermode. The thermode is calibrated on each application in all the subjects. The exact power (and hence the current) needed to obtain a rate of $1^{\circ} \mathrm{C} / \mathrm{s}$ is calculated. Heat transfer and exchange in the skin depend not only on the power applied but also on the physical properties of the skin (see below). The power needed to give the same rate $\left(1^{\circ} \mathrm{C} / \mathrm{s}\right)$ of temperature change ranged between $2800-4200 \mathrm{~mW}$ being higher for the ankle and lower for the wrist and forearm.

6 Stimulus sites. Four different sites for thermal stimulation on the right side were used: (a) The volar aspect of the wrist just proximal to the distal wrist crease, (b) The medial aspect of the ankle where the lower edge of the probe lies posterior to the medial malleolus, (c) The volar aspect of the mid-forearm, (d) The anterior aspect of the thigh midway between the anterior superior iliac spine and the tip of the patella. In order to study contralateral variations, the homologous site on the left forearm was also tested.

Thermal properties of the skin show marked variations between sites leading to differences in the thermal sensitivity of the skin of these sites. ${ }^{25-31}$ These regional variations are greatest at threshold levels. ${ }^{30}$ The amount of energy transferred to the receptor zone determines thermal sensation' which in turn depends on skin thermal conductivity. ${ }^{2730}$ This varies with its physical architecture, chemical and fluid composition, homogeneity of various skin layers, initial skin temperature and most important of all, the epidermal thickness. ${ }^{2731}$ The thicker the epidermis, which acts as an insulating layer, the greater is the resistance against heat transfer to the receptor zone. ${ }^{2731}$ Epidermab thickness varies considerably between sites and from individual to individual. ${ }^{31}$ At the volar aspect of the wrise and forearm (sites (a) and (c)) the epidermis is relativel thin with only negligible interindividual variation. ${ }^{31}$

\section{Subjects and methods}

One hundred and six healthy control subjects, aged between $6-73($ mean $=33, S D=17)$ years, all free of neurological illness and none taking drugs or excessive quantities of alcohol were examined. Of these 45 were $\overrightarrow{\vec{B}}$ male and 61 female. None of them had previous experience of sensory testing. The tests were carried out in a quiet room at a constant temperature of $22 \pm 2{ }^{\circ} \mathrm{C}$. Five sites as described were studied in each patient. The subject was placed in a comfortable position so that the thermode and the weight, taped in place, acted perpendicularly on the site tested. Each subject was placed such that he/she could not see the VDU screen or the digital thermometer on the TIU. All measurements were carried out by the same person (GAJ). The subject was then handed the stimulus indicator and instructed that the two lights would illuminate in sequence at intervals of 30 seconds. With one of the lights a hot (or cold) stimulus would be applied, $D$ immediately following which the subject was forced to choose in which time period the stimulus occurred. $N$ Whenever felt necessary, a short demonstration of the test $\sigma$ was carried out. Heat Threshold (HT) was determined first $N$ followed by Cold Threshold (CT). Some subjects were N tested for all sites in the morning $(n=39)$, others in the afternoon $(n=35)$ while a third group was tested during 
Table 1 Thermal threshold values for 106 normal subjects

\begin{tabular}{|c|c|c|c|c|}
\hline Site & $\begin{array}{l}\text { Type of } \\
\text { threshold }\end{array}$ & $\begin{array}{l}\text { Mean } \\
{ }^{\circ} \mathrm{C}\end{array}$ & $\begin{array}{l}\text { Standard } \\
\text { deviation } \\
{ }^{\circ} \mathrm{C}\end{array}$ & $\begin{array}{l}\text { Upper limit of normal } \\
(99 \% C L) \\
{ }^{\circ} \mathrm{C}\end{array}$ \\
\hline $\begin{array}{l}\text { Wrist } \\
\text { Forearm } \\
\text { Thigh } \\
\text { Ankle }\end{array}$ & $\begin{array}{l}\text { HT } \\
\text { CT } \\
\text { HT } \\
\text { CT } \\
\text { HT } \\
\text { CT } \\
\text { HT } \\
\text { CT }\end{array}$ & $\begin{array}{l}0.23 \\
0 \cdot 15 \\
0 \cdot 24 \\
0 \cdot 15 \\
0.23 \\
0 \cdot 15 \\
1.35 \\
0 \cdot 17\end{array}$ & $\begin{array}{l}0.06 \\
0.05 \\
0.06 \\
0.05 \\
0.06 \\
0.05 \\
0.73 \\
0.06\end{array}$ & $\begin{array}{l}0.40 \\
0.27 \\
0.41 \\
0.29 \\
0.40 \\
0.27 \\
3.28 \\
0.32\end{array}$ \\
\hline
\end{tabular}

$\mathrm{HT}=$ heat threshold $\quad \mathrm{CT}=$ cold threshold

These threshold values represent the change from the basic skin temperature.

both periods $(n=32)$. Both HT and CT determinations were repeated in the right forearm three times at intervals of 24 hours (between the first and the second) and more than two weeks (between the first and the third). In some cases the second interval was up to two months. These intervals were chosen to assess the short and long term reproducibility of the threshold measurement.

\section{Resuits}

Table 1 summarises the results of thermal threshold values given as the deviation from basic skin temperature with mean, standard deviation (SD) and 99\% upper confidence limit for the various sites tested. The normal mean HT for the wrist was $0.23^{\circ} \mathrm{C}\left(\mathrm{SD}=0.06^{\circ} \mathrm{C}\right)$. The $\mathrm{CT}$ was $0.15^{\circ} \mathrm{C}(\mathrm{SD}=$ $\left.0.05^{\circ} \mathrm{C}\right)$.

(1) There was no significant difference in the thermal thresholds between males and females. (2) Both

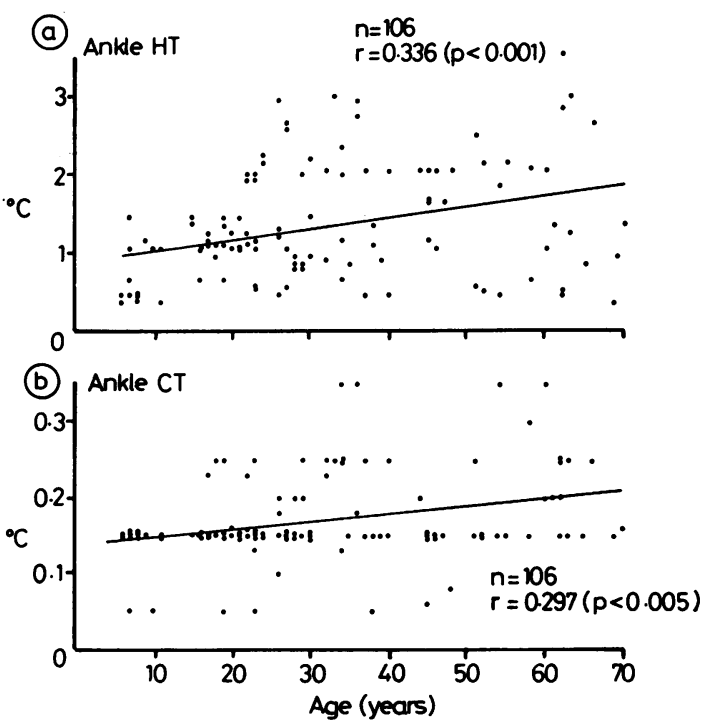

Fig 3 (A) Ankle cold threshold (CT) changes with age. (B) Ankle heat threshold (HT) changes with age. the mean $\mathrm{HT}$ and $\mathrm{CT}$ and respective $\mathrm{SD}$ showed a trend to increase with age at the ankle (fig 3A, B). Many older subjects, however, were as sensitive as younger subjects. There was also a significant linear increase of these thresholds with age for the wrist CT $(r=0.321 ; p<0.001)$ but not in the case of wrist $\mathrm{HT}(\mathrm{r}=0.017$; NS). In 80 subjects above the age of 20 years, the leg length measured from the anterior superior iliac spine to the tip of the medial malleolus did not correlate with HT $(r=0.0225)$ or CT $(r=0 \cdot 195)$. As expected, there was also no correlation between age and leg length $(r=0.0249)$. Subjects above age 20 were selected for this correlation because of the epiphyseal closure after which minimal growth of the leg length occurs. (3) The results of repeated determinations performed on the right forearm are summarised in table 2 . The largest deviation from the initial determinations was $5 \%$. Analysis of variance of heat threshold determination showed significant difference only between the first and the third test two or more weeks later $(p<$ 0.01 ). However, the difference between the first and the third test for HT was approximately one third of the smallest available step in stimulus intensity (see Design). This small change is of no practical significance in the implementation of the technique. No significant difference was noticed between the first and second testings for heat threshold and between first, second and third tests for cold thresholds (table 2). There was a weak trend towards lower values with consecutive determinations of both HT and CT values. (4) After the initial three determinations were done, a further 17 were undertaken daily on two subjects. The range of variation in threshold values was 0 to $0.03{ }^{\circ} \mathrm{C}$ corresponding to a coefficient of variation of 0 to $6 \%$. This is also much less than the smallest available step in stimulus duration. (5) There was no significant correlation between age and the intraindividual variation in the right forearm HT expressed as the difference between first and third determinations $(r=0 \cdot 189)$. (6) There was no significant difference between thermal threshold measured at different times of the day 
Table 2 Consecutive thermal thresholds comparing repeated ipsilateral and contralateral investigations in 106 normal subjects

\begin{tabular}{|c|c|c|c|}
\hline $\begin{array}{l}\text { Site and type of the } \\
\text { thermal threshold }\end{array}$ & $\begin{array}{l}\text { Mean } \\
{ }^{\circ} \mathrm{C}\end{array}$ & $\begin{array}{l}\text { Standard } \\
\text { deviation } \\
{ }^{\circ} \mathrm{C}\end{array}$ & Change in Mean \\
\hline $\begin{array}{l}\text { HT-R Forearm } 1 \text { st } \\
\text { 2nd }(24-48 h)\end{array}$ & $\begin{array}{l}0.243 \\
0.236\end{array}$ & $\begin{array}{l}0.063 \\
0.061\end{array}$ & $-2 \cdot 9 \%\}$ from 1 st investigation \\
\hline 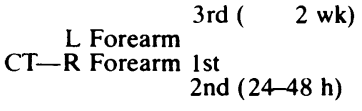 & $\begin{array}{l}0 \cdot 230 \\
0.229 \\
0 \cdot 152 \\
0 \cdot 151\end{array}$ & $\begin{array}{l}0.059 \\
0.059 \\
0.052 \\
0.050\end{array}$ & $\begin{array}{l}-5.3 \% \\
-0.4 \% \text { from } R \text { side } \\
-0.6 \%\end{array}$ \\
\hline L Forearm 3 rd ( 2 wk) & $\begin{array}{l}0 \cdot 148 \\
0 \cdot 142\end{array}$ & $\begin{array}{l}0.051 \\
0.046\end{array}$ & $\begin{array}{l}-2.6 \% \\
-4 \%\end{array}$ from $\mathrm{R}$ side \\
\hline
\end{tabular}

HT $=$ heat threshold $\quad \mathrm{CT}=$ cold threshold

For a discussion of the statistical significance see text

(morning or afternoon) either for HT $(t=0.0524)$ or for CT $(t=0.0114)$.

\section{Discussion}

The consistently lower values for thermal thresholds obtained by our technique contrasts with the higher values obtained by the Marstock method using an identical probe. ' In the latter method the subject was required to switch off the heating (or cooling) one the sensation was appreciated. This introduces a considerable error as once the perception threshold was reached, thermal stimulation continued for a period of time equal to the delay in the afferent pathway (delay of perception) and the subject's reaction time. The measured threshold was therefore greater than the real threshold by the heat produced over that time interval. In our method, where the time of application of heat is predetermined by the computer, this problem does not arise.

We have found that thermal thresholds varied only slightly between wrist, forearm and thigh (table 2 ). The SDs were almost half the smallest step in the stimulus intensity. Ankle HT and to a lesser extent $\mathrm{CT}$ were higher than elsewhere. The reasons for this increase are not known. We have already shown that leg length does not contribute in this context. Thermal thresholds are known to vary in different sites.' "11 is $262724-31$ The skin of the calf has been found to be the least sensitive especially at threshold levels. ${ }^{27.3031}$ This may be due to differences in the thermal properties of the skin. ${ }^{2731}$ A considerable variation in the density of thermal receptors from one region of the skin to another has been reported. ${ }^{113032}$ The density of the heat receptors is absolutely less but their variability is greater than that of the cold receptor. ${ }^{33}$ If these thermal receptors are present in a lower density distally, such might explain the higher thresholds at anklè. It also remains possible that central processing influences temperature appreciation at different sites.

The inter-individual variation by our technique remains small (table 1 ), even at the ankle where variability is greatest, compared with the variation in the Marstock method. ${ }^{10}$ In their automated method Dyck et $\mathrm{al}^{11}{ }^{12}$ have not produced figures for this variability, but examination of their results suggests that it is indeed large. We have extracted data from their graph of normal thermal-cooling thresholds at foot where the range of values at the ages between 10-20 years are from 0.2 to $4^{\circ} \mathrm{C}$ and at the ages between $60-70$ years from 0.3 to $8^{\circ} \mathrm{C} .^{\prime \prime}$ The ankle CT range of values for the corresponding age group 8 with our technique are $0.05-0.25^{\circ} \mathrm{C}$ and 0.15 $0.37^{\circ} \mathrm{C}$ respectively.

The increase of thermal thresholds with age of (figure $3 \mathrm{~A}, \mathrm{~B}$ ) is expected and has been reported in other studies. ${ }^{171112}$ This may be due to a progressive reduction in the number of nerve fibres with age, ${ }^{11} 12$ and/or a decrease in the number of receptors per nerve fibre. ${ }^{32}$ Alternatively, changes in the functional properties of these fibres and/or end organs in the absence of structural changes may be of importance." The increase in thermal thresholds with age was greatest at the ankle.

Intra-individual variation for CT was negligible (table 2). A slight but statistically significant variation of HT between the first and third test, done two or more weeks later, was noted $(p<0.01)$ but not between the first and second or the second and third. However, the greatest change observed was less than $5 \%$, much less than those reported in other studies where differences of up to $150 \%$ were found. ${ }^{10}$ This small intra-individual variation in our technique, which was less than $15 \%$ of the SD and smaller than the smallest step in stimulus intensity, is unlikely to influence the usefulness of the technique for longitudinal follow up of patients. The changes were always towards lower values, perhaps suggesting that a learning process is operative. Intra然 
individual variability in the technique most closely related to ours 1112 is not reported.

The main advantages of the Glasgow method over others in the literature are as follows:

(1) the intensity of the thermal stimulus is varied by altering the stimulus duration. The rate of change of temperature is constant throughout at $1^{\circ} \mathrm{C} / \mathrm{s},(2)$ The thermode is calibrated at each site in each subject to measure the exact amount of power required to obtain a rate of temperature change of $1{ }^{\circ} \mathrm{C} / \mathrm{s}$. This reduces errors due to differences in the thermal properties of the skin at different sites, (3) The thermode pressure on the underlying skin is standardised at all sites, (4) The larger probe reduces the variability of the response,,$^{15}$ (5) The skin sites chosen are those with the smallest variability in thermal properties, (6) The initial skin temperature under the probe is always in the range of $34-35^{\circ} \mathrm{C}$. This significantly reduces variability in thermal thresholds, ${ }^{115-17}$ (7) Threshold determinations take a short time (15-20 minutes for both HT and CT determinations at one site).

We anticipate that this technique will have a wide application in the assessment of function in the thermal pathways and in the study of clinical and subclinical abnormalities of thermal sensation. It will also be valuable in the serial follow up of patients to monitor the progress or the response of an illness to a treatment regimen.

We thank Professor JA Simpson for support and advice. We are indebted to $\mathrm{Mr}$ Colin Burns and other members of the Department of Clinical Physics and Bio-engineering for technical assistance. Our thanks are due to Mrs M McColl for secretarial help and to the control subjects for volunteering to take part in this study. Dr GA Jamal was supported by a grant from Baghdad University, Iraq.

\section{References}

' Kenshalo DR. Psychophysical studies of temperature sensitivity. In: Neff WD ed. Contributions to Sensory Physiology. London: Academic Press, 1970;4:19-69.

2 Dyck PJ, Curtis DJ, Bushek W, Offord K. Description of "Minnesota Thermal Disks" and normal values of cutaneous thermal discrimination in man. Neurology (Minneap) 1974;24:325-30.

${ }^{3}$ Kenshalo OR. Improved method for the psychophysical study of the temperature sense. Rev Sci Instr 1963;34:883-6.

${ }^{4}$ Kenshalo DR, Scott HS. Temporal course of thermal adaptation. Science 1966;151:1095-6.

${ }^{5}$ Hensel $\mathbf{H}$. Cutaneous thermoreceptors. In: Iggo A, ed. Handbook of Sensory Physiology. New York: Springer 1973;2:79-110.

- Kenshalo DR, Bergen DC. A device to measure cutane- ous temperature sensitivity in humans and subhuman species. J Appl Physiol 1975;39:1038-40.

${ }^{7}$ Fruhstorfer H, Lindblom U, Schmidt WG. Method for quantitative estimation of thermal thresholds in patients. J Neurol Neurosurg Psychiatry 1976;39: 1071-5.

${ }^{8}$ Goldberg JM, Lindblom U, Schmidt WG. Temperature sensitivity and pain thresholds in patients with chronic uremia and peripheral neuropathy. In: Zotterman Y, ed. Sensory Functions of Skin in Primates. Oxford: Pergamon Press, 1976:507-17.

${ }^{9}$ Lindblom U, Verillo RT. Sensory functions in chronic neuralgia. J Neurol Neurosurg Psychiatry 1979;42:422-35.

${ }^{10}$ Fagius J, Wahren LK. Variability of sensory threshold determination in clinical use. $J$ Neurol Sci 1981;51:11-27.

" Dyck PJ, Karnes J, O' Brien PC, Zimmerman IR. Detection thresholds of cutaneous sensation in humans. In Dyck PJ, Thomas PK, Lambert EH and Bunge R, eds. Peripheral Neuropathy. London: WB Saunders, 1984; 1: 1103-38.

12 Dyck PJ, Zimmerman IR, O' Brien PC et al. Introduction of automated systems to evaluate touch-pressure, vibration and thermal cutaneous sensation in man. Ann Neurol 1978;4:502-10.

${ }^{13}$ Sekular R, Nash D, Armstrong R. Sensitive objective procedure for evaluating response to light touch. Neurology (Minneap) 1973;23:1282-91.

${ }^{14}$ Wetherhill GB, Chen H, Vasudeva RB. Sequential estimation of quantal response curves: A new method of estimation. Biometrika 1966;53:439-54.

${ }^{15}$ Lele PP. Relationship between cutaneous thermal thresholds, skin temperature and cross sectional area of the stimulus. J Physiol (London) 1954;126:191205.

${ }^{16}$ Lindblom U. Quantitative testing of sensibility including pain. In: Stalberg E, Young RR, eds. Clinical Neurophysiology. London; Butterworth, 1981:16890.

17 Valbo AB, Hagbarth KE, Torebjork HE, Wallin BG. Proprioceptive and sympathetic activity in human peripheral nerves. Physiol Rev 1979;59:919-57.

${ }^{18}$ Lele PP, Weddell G, Williams CM. The relationship between heat transfer, skin temperature and cutaneous sensibility.J Physiol (London) 1954; 126:204-34.

${ }^{19}$ Hendler E, Hardy JD. Infrared and microwave effects of skin heating and temperature sensation. Trans Med Electron 1960;7:114-52.

${ }^{20}$ Vendrick AJ, Eikjman EG. Psychophysical properties determined with internal noise. In: Kenshalo DR, ed. The Skin Senses. Springfield: Thomas, 1968:178-94.

${ }^{21}$ Kenshalo DR, Holmes CE, Wood PB. Warm and cool thresholds as a function of rate of stimulus temperature change. Perception and Psychophysics 1968;3:81-3.

${ }^{22}$ Hilder R, Ramsey E, Darian-Smith KO, Dally LJ. A contact stimulator for the study of cutaneous thermal sensibility. J Appl Physiol 1974;37:252-5.

${ }^{23}$ Molinari HH, Greenspan JD, Kenshalo DR. The effects of rate of temperature change and adapting temperature on thermal sensitivity. Sens Processes 
1977; 1:354-62.

${ }^{24}$ Konietzny $F$, Hensel $H$. The dynamic response of warm units in human skin nerves. Pfuger Arch 1977;370:111-4.

${ }^{2 s}$ Konietzny $F$, Hensel $H$. The neural basis of sensory quality of warmth. In: Kenshalo DR, ed. Sensory Functions of the Skin of Humans. New York: Plenum, 1980;241-56.

${ }^{26}$ Poppendiek HF, Randell R, Breeden JA, Chambers JE, Murphy JR. The thermal conductivity measurements and predictions for biological fluids and tissues. Cryobiology 1966;3:318-27.

${ }^{27}$ Cohen ML. Measurement of the thermal properties of human skin. A review. J Invest Dermatol 1977;69:333-8.

${ }^{28}$ Aschoff J, Wever R. Anisotropy of skin's conductivity. Pfugers Arch 1959;269:130-4.
${ }^{29}$ Nadel ER, Mitchell JW, Stolwijk JAJ. Differential thermal sensitivity on the human skin. Pfugers Arch 1973;340:71-76.

${ }^{30}$ Stevens JC, Lawrence EM, Simonson DC. Regional sensitivity and spatial summation in the warmth sense. Physiol Behav 1974;13:825-36.

${ }^{31}$ Stoll A. Thermal properties of human skin related to non-destructive measurement of epidermal thickness. J Invest Dermatol 1977;69:328-32.

${ }^{32}$ Wall PD. Somatosensory mechanisms. In: Cobb WA, ed. Somatic Sensation. Handbook of Electroencephalography and Clinical Neurophysiology. Amsterdam: Elsevier, 1977;9:1-7.

${ }^{33}$ Light AR, Perl ER. Peripheral sensory systems. In: Dyck PJ, Thomas PK, Lambert EH and Bunge R, eds. Peripheral Neuropathy. London: WB Saunders, 1984;1:210-30. 